\title{
OPTICAL, WIRED AND WIRELESS MULTIMEDIA SERVICE ACGESS SOLUTIONS FOR TREND SETTING REAL ESTATES
}

It is a well known fact that the value of real estates is raised tremendously by its connection to information technology services like Voice over IP (VoIP), IPTV, Video on Demand (VoD), basic Internet services and house-, security- and surveillance technologies. This paper will focus on different state of art methods to connect a real estate to the above mentioned services and will also discuss various inhouse cabling systems and related devices. Advantages and disadvantages between the miscellaneous combinations will be discussed.

Keywords: FSO, multimedia, broadband Internet, optical networks, VoIP, IPTV, videoconferencing

\section{Introduction}

In the next decades the economic future will lead Europe in a position to be more and more a supplier of services than of commodities. Because of cheap manufacturing costs imports are done from other low wage countries (e.g. China). The production of goods in Europe will get more and more expensive, the customers and the market will choose cheaper imports. This is a harmful evolution for the European economy. Therefore effective strategies have to be evolved to be competitive. At least Europe has to be a global provider for engineering, intellectual and other high quality services. Taking into account the latter enumerated services the future good will be the high quality global communication and information exchange.

Right now there is already a strong trend and demand for interactive social networks, like Internet TV, online communities, new services and forms of interactive living (video-conferencing). A current example of emerging services is the interactive ubiquitous and convergent Grand Media Internet TV portal. This portal enables its users to upload and broadcast content to their specific audiences, allows multimedia e-commerce and communication services via the Internet and supports with mobile user end devices. An additional set top box offers these services also for widespread classic TV sets [1]. A very promising future demand will be the combination of such platforms with house-, security- and surveillance services.

However, all these services require guaranteed synchronous broadband Internet services. In entire Europe the performance of the last mile access usually does not satisfy this future demand. Telecommunication companies use their outdated copper networks and are not interested to invest into next generation fiber networks. Especially in Austria there is the common situation that WIMAX frequency licenses auctioned by the local telecommunication regulator are held and not used by monopolistic telecommunication providers. The possible reasons for this attitude are doubtful and also hostile to innovation.

Current trends show that the volume of the Internet traffic until 2012 will be multiplied by the factor of 6 due to the emerging field of online videos.

In Austria there have been initiatives by the local governments to provide the population with so called broadband Internet based on copper lines. In reality the broadband initiatives provide asynchronous lines with $0.3 \mathrm{Mbit} / \mathrm{s}$ upload and $1 \mathrm{Mbit} / \mathrm{s}$ download. The International Telecommunication Union (ITU-T) standardization recommendation I.113 has defined broadband as a transmission capacity that is more than 1.5 to $2 \mathrm{Mbit} / \mathrm{s}$ [2].

Because of this unsatisfying situation and the lack of reasonable fiber optic infrastructure which is not provided by monopolistic telecommunication companies, this paper will concentrate on alternative last mile access technologies to real estates to satisfy the future broadband demand. Especially local and regional communities, societies and service providers could be a veritable concurrency with their local networks.

These technologies will provide companies, societies and citizens with genuine broadband services, also environmental and economic factors like global warming and $\mathrm{CO}_{2}$ issues can be improved.

When we are talking about real estates in the following sections, we basically reckon buildings within a settlement or residentials with a reasonable amount of units. Having just a single building, a lot of factors like central maintenance and service purchase, high flexibility, homogenous services and technologies cannot be achieved in terms of low costs. Especially these costs rise the value and the attractiveness for possible real estate investors and customers.

\footnotetext{
* P. Mandl ${ }^{1}$, P. Schrotter ${ }^{2}$, E. Leitgeb ${ }^{1}$

${ }^{1}$ Graz University of Technology, Institute of Broadband Communications, Graz, Austria

${ }^{2}$ Graz University of Technology, Institute of Communication Networks \& Satellite Communications, Graz, Austria, E-mail: peter@mandl.org
} 


\section{Last mile broadband access technologies to real estates}

In this section we will present the function of several broadband last mile access technologies and will show advantages and disadvantages. The definition of broadband Internet services in this publication will include several services like IPTV, Voice over IP (VoIP), Video on Demand (VoD) and all well known basic Internet services (e.g. email, www). These services will be based on access technologies like DSL, Fiber to the Home (FTTH), Free Space Optics (FSO), WIMAX, WLAN and Digital Video Broadcasting - Terrestrial (DVB-T) and its future variants. It is the basic idea to have one general service provider which is connected to a standardized flexible "data interface" like copper twisted pairs, coaxial cable and fibers into the real estates.

To understand the different services and to weight its "bandwidth cost", Tab. 1 shows the different average bandwidth consumption per service.

Tab.1 also significantly shows that services like VoD, IPTV and videoconferencing consume most of the bandwidth, especially with high definition content.

VoD is a technology based on unicast video streams. Each user gets an individual unicast data stream when he decides to consume a specific content. The total bandwidth is increased directly proportional to the number of unique users or video streams.

IPTV usually is provided via multicast streams and is comparable with the classic TV. The number of provided TV channels is the factor for calculating the backbone bandwidth. This has especially to be taken into account when a real estate is providing HDTV services. The data rate is a multiple of the standard definition (SD) data rate. A fix amount of the access bandwidth according to the number of provided TV channels has to be preserved for their proper function. The worst case scenario is, that all different channels are watched at the same time by all users, causing insufficient bandwidth which is not available for other services (e.g. emergency calls). This has to be avoided strictly in the planning phase.
Videoconferencing is a technology where two or more users can communicate with video and audio streams. Both users can see and hear each other at the same time which requires a synchronous data connection. Especially IPTV and videoconferencing in high definition quality consumes very much bandwidth ranging from $0.5 \mathrm{Mbit} / \mathrm{s}$ up to $12 \mathrm{Mbit} / \mathrm{s}$ depending on the purpose. In general the bandwidth of $30 \mathrm{Mbit} / \mathrm{s}$ will not be reached but in applications which requires a very high resolution (e.g. the transmission of a medical surgery), or for independent end devices.

Regarding the emerging trend of video services in the Internet, it is remarkable that most of the used Internet lines worldwide are asynchronous (e.g. ADSL, DOCSIS). Most Internet access lines do not have a guaranteed bandwidth (Committed Information Rate - CIR), which will be a future bottleneck.

\subsection{DSL technologies based on copper lines}

In entire Europe the DSL (Digital Subscriber Line) technology is one of the most widespread technologies for the last mile access. By using a DSLAM (Digital Subscriber Line Access Multiplexer) and a corresponding DSL modem the connection to the user is established physically. The practical experience shows these services often have a lack of bandwidth. Most copper lines which are leased by Internet service providers are outdated, sometimes the initial cable installation goes back to the $19^{\text {th }}$ century. Hence the cables often are in bad shape and the connection is affected by high attenuation and connection losses at higher bit rates. Usually the copper lines have to be rent from monopolistic telecoms. The providers are basically allowed to use a gross bit rate of 2.36 Mbit/s for payload transfer with a net bit rate of $2048 \mathrm{Kbit} / \mathrm{s}$ over this copper line pair. The signals have to be defined accordingly to ETSI TS 101524 (SDSL) and ETSI TR 101 830. It is a fact that ISP's usually do share the bandwidth for economical reasons with a number of users (overbooking). A minimum guaranteed bit rate, the Committed Information Rate (CIR) is neither offered nor desired by ISP's) in most cases. For the common implementation of genuine multimedia services in real estates this access technology is just of limited applicability.

\begin{tabular}{|c|c|c|}
\hline Service & Bandwidth & Protocol \\
\hline House-, Security technologies & $0.001-0.1 \mathrm{Mbit} / \mathrm{s}$ & TCP(IP) \\
\hline Voice over IP (VoIP) & $0.01-0.1 \mathrm{Mbit} / \mathrm{s}$ per call & TCP(UDP) \\
\hline Surveillance technologies & $0.5-1 \mathrm{Mbit} / \mathrm{s}$ per stream & TCP(IP) \\
\hline VoD & $0.5-1 \mathrm{Mbit} / \mathrm{s}$ per stream & TCP(IP) \\
\hline Basic Internet services & up to $1 \mathrm{Mbit} / \mathrm{s}$ & IP Multicast \\
\hline IPTV & 0.5 to $5 \mathrm{Mbit} / \mathrm{s}$ per channel & TCP(IP) \\
\hline Videoconferencing & 0.5 to $5 \mathrm{Mbit} / \mathrm{s}$ per channel & IP Multicast \\
\hline IPTV HD & 1.5 to $12 \mathrm{Mbit} / \mathrm{s}$ per channel & TCP(IP) \\
\hline Videoconferencing HD & 1.5 to $12 \mathrm{Mbit} / \mathrm{s}$ per channel & \\
\hline
\end{tabular}




\subsection{FTTH}

Fiber To The Home (FTTH) is the most interesting technology to connect a real estate to convergent information technology services. This is based on the theoretical bandwidth of a single fiber which is just limited by the accuracy of optical filters (number of wavelengths, WDM, DWDM) and the throughput of the Ethernet switch backplanes and ports. The latter facts are characteristics for a next generation infrastructure which will be adaptable to the users needs and state of technology. Higher bandwidths can be achieved by simply changing slower with faster active network components.

In general we can divide the FTTH access methods into two main groups:

\subsubsection{Direct fiber connection}

This approach connects a network operation centre (NOC) directly with the user's end device with at least one single fiber. By using bidirectional data transfer mode it delivers the highest performance to the user. For such a connection two different wavelengths for the up- and downlink are used. Because of the amount of required Ethernet switches and ports, every user gets one centrally switched fiber, this solution in fact is very expensive. Every user needs at least one switch port that has to be managed and serviced which produces additional costs.

\subsubsection{Passive Optical Network (PON)}

The main advantage of PON is the architecture transferring data point-to-multipoint with passive optical units. Hence these units are not required to have an electrical power supply, and no specific or additional management or maintenance is necessary.

Basically a PON consists of a network operation centre (NOC) including an optical line terminal (OLT), one or more distribution nodes (Optical Network Units, ONUs) and the fibers and splitters between them, which are called the optical distribution network (ODN).

The Passive Optical Networks did evolve from the ITUT G.983 standard. The first realisations have been APONs (ATM Passive Optical Networks) and BPONs (Broadband PONs). Afterwards the GPON (Gigabit PON, ITU-T G.984) was the successor of the former standard which enables higher bit rates and security features. EPON or GEPON (IEEE 802.3ah) is the corresponding IEEE standard for using this technology for Ethernet data transfer.

PON uses two different wavelengths (wavelength division multiplex, WDM) for the up and downlink. Current systems can transport $2.4 \mathrm{Gbit} / \mathrm{s}$ of downstream bandwidth, and $1.2 \mathrm{Gbit} / \mathrm{s}$ of upstream bandwidth within a range of $20 \mathrm{~km}$ by a single fiber.

There is already a new standard, IEEE 802.3av (10GPON), which allows the use of more wavelengths enabling to higher bit rates per single fiber.

\subsection{FSO - Free Space Optics}

A free space optics data transfer system (FSO, Fig. 1, Fig. 2) is a very flexible broadband access solution offering high data rates without long cabling for the mobile access to backbone networks $[3,4,5,6]$. In difference to other mobile data transfer methods (e.g. point-to-point radio systems) a FSO system has outstanding

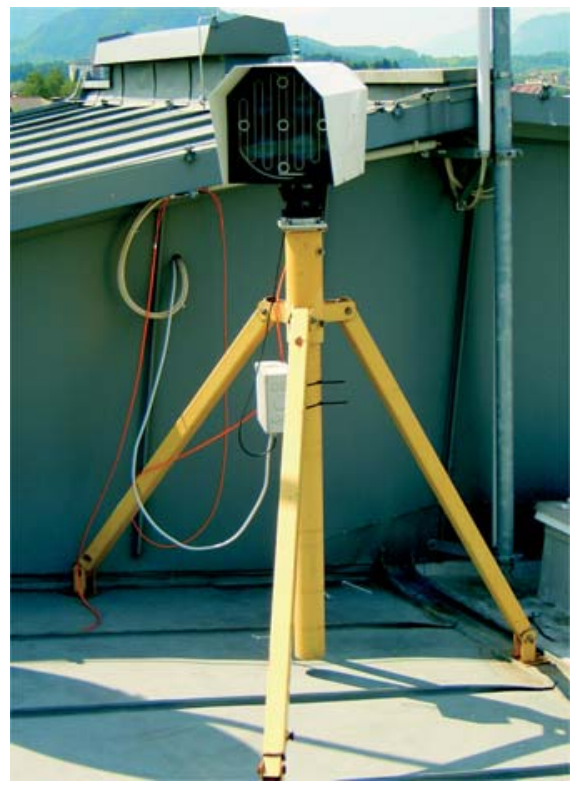

Fig. 1 FSO Unit

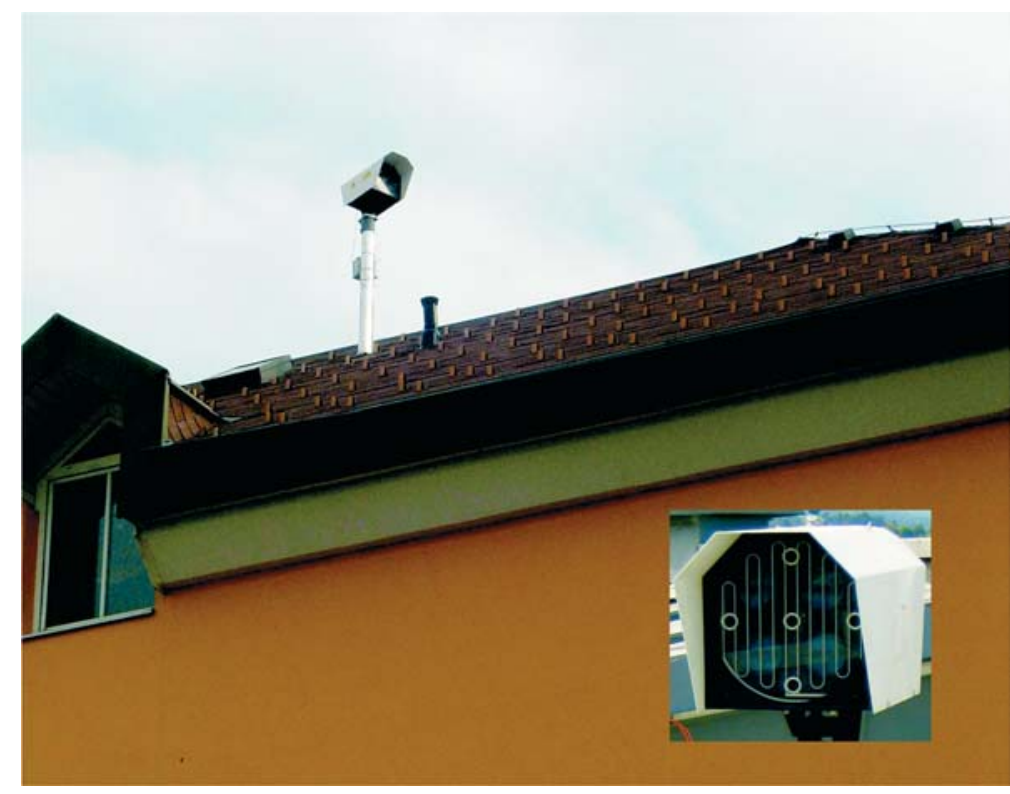

Fig. 2 FSO unit mounted on a roof, detail front view 
advantages like higher bandwidth, better ability to concentrate beams, simpler assembling and disassembling, better beam bundling, no license fees for the usage of radio channels, better security against wiretapping and also better environmental compatibility (no electromagnetic pollution). Disadvantages are atmospheric influences like rain, snow, fog and direct sun beams.

Today FSO systems are used for the quick setup of low range inner city links (point-to-point), broadband links over motorways, rail tracks or over rivers as well as for the wiretap-proof connection between company buildings and corresponding institutions. Further applications could comprise the connection of mobile emergency response services and other equipment of executive authorities, the fire brigade, and armed forces to a backbone network during crisis operations. For these reasons FSO is the ideal technology to operate within the above mentioned cases and many more scenarios. A FSO system which offers a bidirectional pointto-point connection consists of two separated OSE's (optical sending and receiving unit) with integrated receiving (PIN diodes) and transmitting devices (laser diodes). Typical FSO data rates range from $100 \mathrm{Mbit} / \mathrm{s}$ up to $1.5 \mathrm{Gbit} / \mathrm{s}$.

According to standardized laser classes the output power is restricted for health safety measures [7]. The typical fog attenuation in Austrian regions, the main limitation for an FSO link, is specifically about $100 \mathrm{~dB} / \mathrm{km}$. To overcome this, the laser power can be increased up to more than $500 \mathrm{~mW}$ (laser class 4B) which can cause eye damages. Hence the position of the OSE's has to be selected carefully to reduce the possibility of health damages.

FSO systems on sea vessels with auto tracking units have been reported to bridge $25 \mathrm{~km}$ offering a data rate of up to $1.5 \mathrm{Gbit} / \mathrm{s}$ by using up to $7500 \mathrm{~mW}$ of laser power [12]. The nomadic use of a FSO system with multimedia applications using $100 \mathrm{Mbit} / \mathrm{s}$ over $1.2 \mathrm{~km}$ have already successfully been demonstrated $[8,9,11]$. Within a settlement or a group of real estates FSO is a very effec-
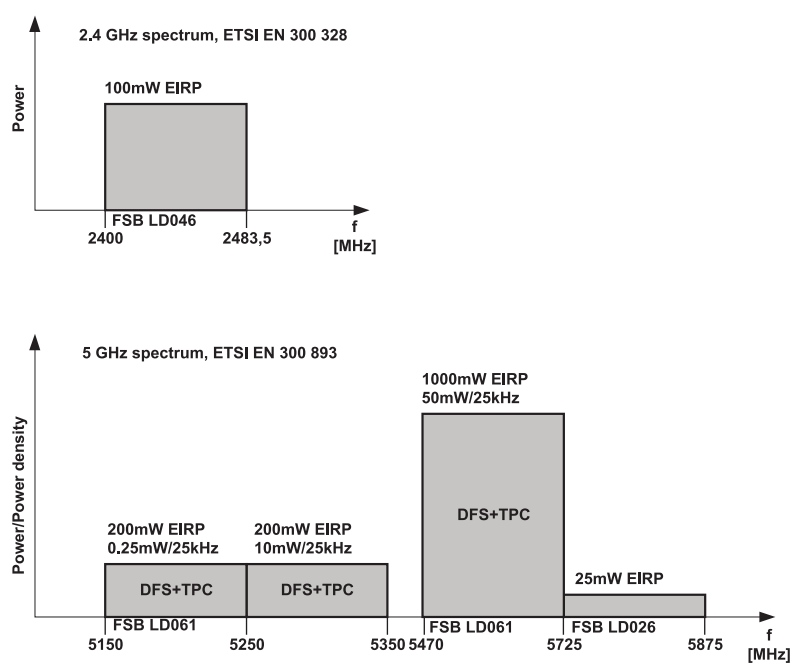

Fig. 3 License exempt frequency spectrums according to ETSI tive solution to interconnect buildings without additional excavation.

\subsection{WIMAX}

WIMAX (Worldwide Interoperability for Microwave Access) is a technology that provides wireless data via radio frequency point-to-point or point-to-multipoint links and also enables full mobile cellular type access. WIMAX is based on the IEEE 802.16 standard and the frequency use is license based.

The licences usually are auctioned by the local governments or telecommunication regulators. WIMAX is a very interesting technology regarding the output power of up to $4.5 \mathrm{~kW}$ ERP and a synchronous bandwidth of $100 \mathrm{Mbit} / \mathrm{s}$ per base station which enables an operating range of up to $20 \mathrm{~km}$. The user's connection to a WIMAX base station is established with a simple end device and an appropriate antenna installation.

We already mentioned, in Austria all WIMAX licenses are owned by those who currently do not use or rent these frequencies. The current situation inhibits the use of this interesting technology.

\subsection{WLAN}

WLAN IEEE 802.11a, b, g, $\mathrm{n}$ is a widely used technology for wireless network connections. Public frequencies are free to use for everybody within the allowed transmission power (EIRP) for the specific frequency range (Fig. 3).

Depending on the standard there are two frequencies used, 2.4 and $5 \mathrm{GHz}$. Regarding the free space loss and the allowed EIRP it has been shown that the $5 \mathrm{GHz}$ band is better suited for

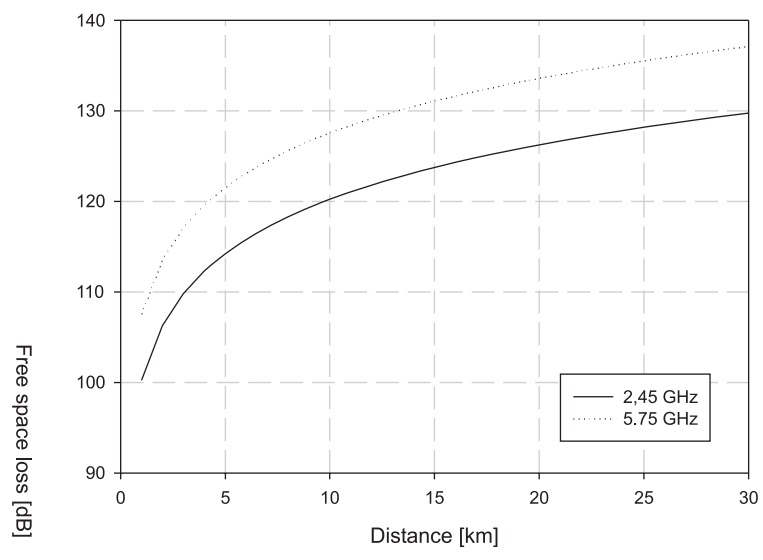

Fig. 4 Comparison between free space losses of 2.4 and $5 \mathrm{GHz}$ 
long range connections with directed radio antennas between two WLAN transceivers (Fig. 4).

By calculating the link budget for the $5 \mathrm{GHz}$ band within the allowed EIRP there is a link margin of $11 \mathrm{~dB}$ for a link length of $5-10 \mathrm{~km} \mathrm{[10].} \mathrm{With} \mathrm{such} \mathrm{a} \mathrm{link} \mathrm{it} \mathrm{is} \mathrm{possible} \mathrm{to} \mathrm{provide} \mathrm{a} \mathrm{band-}$ width of net $60-90 \mathrm{Mbit} / \mathrm{s}$ in line of sight situations.

\subsection{DVB-T with WLAN backchannel}

Digital Video Broadcasting - Terrestrial (DVB-T) is a relatively new technology for transmitting digital data in a specific local region. It transmits a compressed video/audio stream using the OFDM modulation. For the compression of the data usually the MPEG2 or H264 algorithm is used. Usually DVB-T is used for broadcasting digital TV channels. A DVB-T transmitter multiplexes a couple of TV channels into one program stream, comparable to the technology used in satellite TV broadcasting (DVB-S). The bandwidth of a program stream can reach from 5 to about $32 \mathrm{Mbit} / \mathrm{s}$. The user of the service is required to have a Set Top Box (STB) or ITV which is able to receive, demultiplex and decode the selected channel.

DVB-T basically allows to broadcast video via the program stream and additionally enables the transfer of data, for example by the IP over DVB standard [13]. Several backchannels (e.g. GPRS, 3G, POTL) are enumerated in this standard.

To operate a DVB-T transmitter also requires a frequency license. The TV broadcasting in Austria has changed from analogue to digital transmission during the last year. Because of the topographic situation a certain amount of DVB-T stations especially in mountain and valley regions have to be installed to achieve an intended coverage. Usually these regions also lack of appropriate Internet broadband services. Currently the Austrian gov- ernment supports providers in setting up these regional DVB-T broadcasting stations. This could be a chance to connect peripheral real estates with reasonable Internet services using DVB-T data transfer on downlink and WLAN IEEE 802.11, especially in the $5 \mathrm{GHz}$ frequency band, as a license free and cheap backchannel (Fig. 5).

\section{Central IT systems and inhouse cabling}

This section will describe the function of a central IT system in a real estate. Further on the variety of connection possibilities to the units in a building will be analyzed and discussed.

\subsection{Central IT systems}

The core of the real estate consists of several parts. The main idea is to have a flexible interface to connect one or more of the above discussed Last Mile Access Technologies. This interface is connected to a basic system composed of an Internet firewall, a router and an Ethernet switch with a number of ports according to the number of users or individual units. Recent Ethernet switches are capable to select the layer 1 connection by the type of modules (copper or fiber) which are plugged into the switch ports. The chassis, backplane and switching unit of the switch always remains the same, the physical switch port type can be selected very flexible and according to the needs. Also the physical uplink port type to the specific service provider can be selected by inserting and using an appropriate module. The bandwidth of current uplink modules ranges up to $10 \mathrm{Gbit} / \mathrm{s}$ per wavelength and connection.

In general the total bandwidth can be increased by adding more switches and/or uplink ports which connects to the service provider, also by different methods.

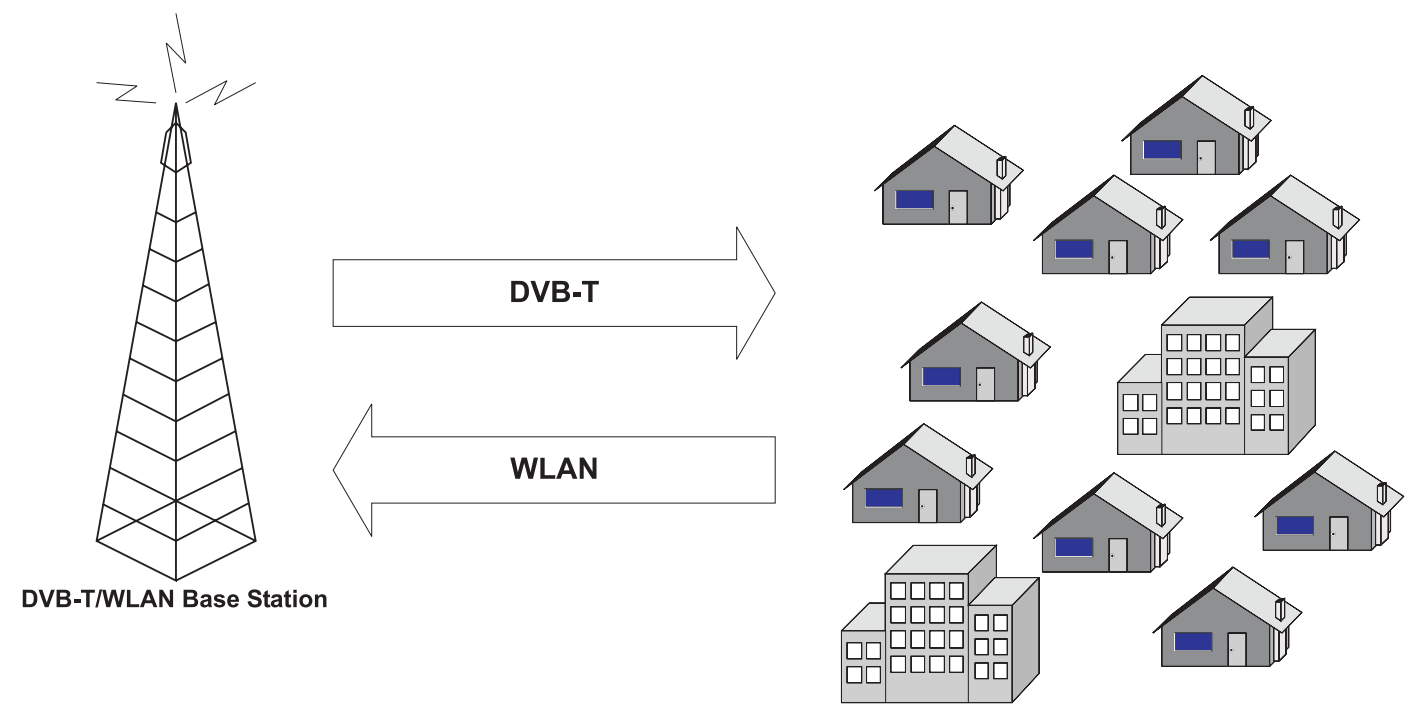

Fig. 5 DVB-T downlink and WLAN as a backchannel for Internet services 
The real estates central IT system also should have capabilities for local network management, an uninterrupted power supply unit, local proxy servers for $\mathrm{VoD}$ services to keep the network traffic low and a local telephone system with a GSM or ISDN backup line for emergency calls during connection line failures. The listed equipment can easily be mounted in a single space saving 19" rack.

\subsection{Inhouse cabling}

There are a couple of methods to connect individual units to the central distribution point. We have to divide between elder buildings which already are equipped with existing cabling systems and novel buildings.

\subsubsection{Existing real estates}

One of the widespread cabling technologies to individual units in a real estate is coaxial cabling. Usually the intermediate frequency of a satellite LNB is distributed via these cables. By using the bus architecture of this cabling there is a technology existing to provide users with synchronous Internet services. Using this technology which is similar to coaxial Ethernet systems (e.g. Token Ring, 10Base2) used in the last decade, up to $100 \mathrm{Mbit} / \mathrm{s}$ synchronous can be supplied from a master device to a number of client devices in the units (ITU-T Rec. G.9954). The bandwidth for a single user simply can be planned and configured on the client device taking into account the sum of users connected to the master bus.

Using a Cable Modem Termination System (CMTS) similar to large Internet Service Providers in one or a group of real estates is an uneconomical technology. These systems in the leanest construction are designed to provide more than 5000 users. This concentration of users usually is not reached in a complex of buildings. A CMTS also shows another disadvantage, it is not able to supply synchronous data transfer. This feature is not intended by the DOCSIS (Data Over Cable Service Interface Specification, ITUT Rec. J.112) standard for these systems, which disqualifies this system to be used in trend setting real estates.

One also has to take into account that replacing an existing cable system by another (e.g. CATx or fiber) is an expensive and dust creating task. Often owners of a real estate are not willing to authorize these reconstructions.

To have a future proof solution, an existing coaxial cabling should be replaced in case of high attenuation or an installation period of more than 20 years by either fiber or CATx cables. These two different cable types have to be selected regarding to the planned services, purpose or depending on the average connection length in a building.

\subsubsection{New built real estates}

In case of the construction of a novel real estate there is a variety of different methods for inhouse cabling which can be considered in the planning phase to connect units to the backbone:

\subsubsection{Coaxial cable in combination with a CMTS or similar system}

In most cases of existing buildings the coaxial cabling is not suitable for data transfer: High attenuation due to the age of the cable and the wrong cabling architecture because of its purpose to broadcast satellite TV signals make a coexistence with a CMTS impossible.

Even with a new cabling a cost value analysis with this architecture is negative due to the high investment cost of a CMTS and the low bandwidth performance.

\subsubsection{Structured cabling standards CAT 5e, CAT 6, CAT 7}

A very flexible solution is the use of the well known CAT standards (Cable and Telephone). These cables usually consist of shielded twisted copper pairs which are defined in several categories. For the multimedia inhouse cabling CAT 5e (TIA/EIA-568B.2.2001), CAT 6a (ANSI/TIA/EIA-568-B.2-10), CAT 7 (ISO/IEC 11801:2002) be considered as reasonable candidates. CAT 5e can transport up to $1 \mathrm{Gbit} / \mathrm{s}$ with a cable length up to $100 \mathrm{~m}$, while CAT $6 \mathrm{a}$ is able to transfer up to $10 \mathrm{Gbit} / \mathrm{s}$ (10Gbase-T) in the same range.

CAT 7 already is capable of transferring $10 \mathrm{Gbit} / \mathrm{s}$. It also has currently been reported that this standard will be able to transfer $100 \mathrm{Gbit} / \mathrm{s}$ within a range of $100 \mathrm{~m}$ in 2013 [14].

\subsubsection{Passive/active fiber cabling to the units}

Taking the PON approach, every unit gets a single fiber, no more switching devices in the real estates central IT unit have to be installed. The switching is done by passive units instead of expensive and error prone fiber switches. This is the most economical and efficient way to connect a real estate to a service backbone. One single fiber from a central NOC is connected to a passive optical switch in the real estate which is connected to all units. By using different wavelengths (DWDM, WDM) to supply a complete unit or single end device the bandwidth can be raised easily for the future demands without changing expensive hardware components. 


\section{Conclusions}

We have described the different access technologies and advantages in the previous sections. Tab. 2 gives an overview, which services can be used by a specific access technology.
RF based solutions do not have the optimal bandwidth performance for (HD) multicast IPTV or high quality video conferencing, but give a promising possibility to connect isolated settlement areas with broadband services. Especially DVBT services like IPTV and videoconferencing in either standard or high definition are expen-

Overview services per access technology

Tab. 2

\begin{tabular}{|c|c|c|c|c|c|c|}
\hline Service/Technology & XDSL & FTTH & FSO & WIMAX & WLAN & DVBT with WLAN \\
\hline House-, Security technologies & yes & yes & yes & yes & yes & yes \\
\hline VoIP & yes & yes & yes & yes & yes & yes \\
\hline Surveillance technologies & yes & yes & yes & yes & yes & yes \\
\hline VoD & yes & yes & yes & yes & yes & yes \\
\hline Basic Internet services & yes & yes & yes & yes & yes & yes \\
\hline IPTV (multicast) & yes & yes & yes & no & no & no \\
\hline Videoconferencing & yes & yes & yes & yes & yes & no \\
\hline IPTV HD & no & yes & yes & no & no & no \\
\hline Videoconferencing HD & no & yes & yes & no & no & no \\
\hline
\end{tabular}

FTTH with either active or passive PON has been shown the best future proof solution to connect real estates to capacious broadband Internet services. It is the current situation that fiber cables are not available to the buildings where it would be needed. For these reasons and also for the economic future of Europe there have to be done specific infrastructure investments by the European Union and/or local governments.

Connecting a real estate with FTTH usually creates construction costs. To reduce these costs the water connection which leads inside the building can be used. The pipe diameters range up to 2 " depending on the number of users and the water throughput. It is an interesting approach to connect the building with fiber cables via these pipes. A certain amount of construction costs (digging and core drilling) can be saved [15].

The second best alternative to connect and interconnect real estates with the mentioned and more broadband services is a FSO system. To reduce line failures to a minimum an FSO ring architecture can be established between single buildings.

RF based solutions are an interesting approach for peripheral areas where the installation of fiber cables is an expensive venture, especially in rural areas with low population density. Unfortunately sive methods in terms of hardware. In comparism to satellite transmissions DVBT provisioning is very much lower because of the given topological situations. Economically spoken, a satellite transponders coverage reaches much more users with higher bandwidth than a single DVBT transmitter. Even if the number of DVBT stations is formidable increased, a satellite transponder is cheaper and more effective.

The recommended future proof solution for inhouse cabling of a trend setting real estate delivering its users high quality and economic services is using either structured cabling (CAT standards, especially CAT 7 with up to $100 \mathrm{Gbit} / \mathrm{s}$ ) or a single fiber connected to a supplying PON.

Comparing all above mentioned methods, a general recommendation and reliable economical estimation per method cannot be done at this time. Hence these solutions are mostly just testbeds which are not in a global rollout, the adequate solution has to be developed taking into account the specific economical aspects as the cases arise.

\section{Acknowledgements}

The authors wish to acknowledge the assistance and support of GM1.TV and Cisco Systems.

\section{References}

[1] http://www.gm1.tv

[2] http://www.itu.int/publications/default.aspx

[3] LEITGEB, E., GEBHART, M., FASSER, P.: Reliability of Free Space Laser Communications - Investigations at the TU Graz, 8th WCA Technical Symposium, 2002, CDROM

[4] LEITGEB E., BREGENZER, J., FASSER, P., GEBHART, M.: Free Space Optics - Extension to Fiber-Networks for the "Last Mile", Laser and Electro-Optics Society, 2002, 15th annual meeting of IEEE, vol. 2, p. 459-460

[5] LEITGEB, E., BREGENZER, J., GEBHART, M., FASSER, P., MERDONIG, A.: Free Space Optics - Broadband Wireless Supplement to Fiber-Networks, LASE, 2003, vol. 4975, p. 57-68 
[6] LEITGEB, E., GEBHART, M., BIRNBACHER, U., SHEIKH MUHAMMAD, S., CHLESTIL, CH.: Applications of Free Space Optics for Broadband Access, OPNETEC, 2004, p 579-586

[7] IEC/EN 60825-12: 'Safety of laser products - Part 12: Safety of free space optical communication systems used for transmission of information'

[8] LEITGEB, E., GEBHART, M., BIRNBACHER, U., SCHROTTER, P., MERDONIG, A., TRUPPE A.: Hybrid Wireless Networks for Civil-Military-Cooperation (CIMIC) and Disaster Management, SPIE, 2004, vol. 5614, p. 140-145

[9] LEITGEB, E., GEBHART, M., BIRNBACHER, U.: Optical networks, last mile access and applications, Journal of Optical and Fiber Communication Reports, 2005, Rep 2, p. 56-85

[10] SAUNDERS, S. R., ARAGON-ZAVAlA, A.: Antennas and Propagation for Wireless Communication Systems, Second Edition, John Wiley \& Sons, 2007

[11] MANDL, P., CHLESTIL, CH., ZETTL, K., LEITGEB, E.: Hybrid systems using Optical Wireless, Fiber Optics and WLAN for temporary multimedia applications, $9^{\text {th }}$ International Conference on Telecommunication, ConTel 2007, p. 73-76

[12] EPPLE, B., HENNINGER, H.: Discussion on Design Aspects for free-Space Optical Communication Terminals, IEEE Communications Magazine, October 2007, p. 62-68

[13] EN301192: Specifications for Data Broadcasting, European Telecommunications Standards Institute (ETSI), 2004

[14] HODGIN, R.: Cat-7 copper theorized to transmit $100 \mathrm{Gbit} / \mathrm{s}$ in exec of 100 meters using future modem, TG Daily

[15] DIN IEC 60794-3-60: Optical fibre cables - Part 3-60: Outdoor optical fibre cables - Family specification for drinking water pipe cables and sub-ducts for installation by blowing and/or pulling/dragging in/floating into drinking water pipes (IEC 86A/1140/CD:2007). 